\title{
USING CAMERA - TRAP DATA TO MODEL HABITAT USE BY WOMBATS AND CATTLE IN AUSTRALIAN RIPARIAN ECOSYSTEMS
}

\author{
BORCHARD, P.* \\ School of Biological Sciences A08, University of Sydney, NSW 2006, Australia \\ *Corresponding author \\ e-mail: pbor6081@usyd.edu.au \\ (Received $26^{\text {th }}$ September 2008; accepted $29^{\text {th }}$ January 2013)
}

\begin{abstract}
Common Wombats (Vombatus ursinus) are an enigmatic south east Australian agricultural riparian species which may improve riparian landscape heterogeneity via their burrowing activity. At the same time they are often accused of causing soil erosion. As populations of wombats in other landscapes are under threat due to habitat disturbance, road mortality and disease, knowledge of the factors determining their distribution and abundance are important for their conservation and management. Since the European colonization of Australia, riparian areas have been utilized by domestic cattle (Bos taurus) usually resulting in a decline in biodiversity. Camera trap data was used to investigate the habitat use by wombats and cattle in Eastern Riverine Forests. The relationship between camera trapping and ecological and meteorological variables was investigated using logistic regression modelling. Wombats and cattle were the most common mammals recorded across all sites with 468 photographs of wombats and 106 of cattle recorded. The meteorological and ecological variables that had a significant effect on the observation of a wombat or a cow were time of day, humidity, lower storey canopy cover and the summer season. This study highlights the usefulness of camera trapping as a tool of conservation and management in an agricultural riparian landscape.
\end{abstract}

Keywords: wombat, burrowing, cattle, riparian, habitat use

\section{Introduction}

Common Wombats (Vombatus ursinus) are an enigmatic component of south eastern Australian agricultural riparian ecosystems. Wombats may fulfil important ecological roles such as disturbing soil and increasing landscape heterogeneity through their burrowing activities, much as other burrowing animals do elsewhere in the world (Reichman and Seabloom, 2002). As a consequence of these activities, they are often also accused of causing soil erosion (Borchard and Collins, 2001; Marks et al., 1989). Populations of wombats are under pressure, however, from habitat disturbance, road mortality and disease (Roger et al., 2007), so that an accounting of their impacts is important to inform effective management.

In agricultural riparian landscapes, wombats often occur in high density populations (McIlroy, 1973; Skerratt et al., 2004; Taylor, 1993). In these environments wombats use the sloping streambanks for burrow sites, with adjoining agricultural pastures providing an abundant food source (McIlroy, 1973; Skerratt et al., 2004; Taylor, 1993).

While wombats appear to be presently coexisting with agricultural production, knowledge of the factors determining their distribution and abundance is important for their long - term conservation. Habitat requirements for wombats in remnant riparian forests that extend through agricultural landscapes have been rarely quantified, nor have models been developed. However, several ecological studies undertaken throughout the distributional range of wombats (Buchan and Goldney, 1998; Catling and Burt, 1995; Lunney and O'Connell, 1988; McIlroy, 1973; Murray, 2001; Taylor, 1993) provide 
important evidence as to which ecological factors might predict habitat quality for the species.

Wombats are typically associated with eucalypt forests (Catling and Burt, 1995; Lunney and O'Connell, 1988; McIlroy, 1973). In the narrow riparian forests that extend through agricultural land, however, lower canopy cover may be an important determinant of abundance, as it also appears to be for burrow site selection (Borchard et $a l$,. In Press). Litter cover is also likely to be an important factor influencing habitat quality, with wombats often observed scratching in friable soil while depositing scats (Triggs, 1996).

Time of day is important predictor of wombat habitat use due to the mainly nocturnal habit of the species (McIlroy, 1973), and season, temperature and humidity may also be important predictors of riparian habitat use.

A key factor that has limited quantitative habitat modelling for wombats is the difficulty of reliably estimating density or even relative abundance. This is because of the nocturnal nature of wombats and the associated problems of directly sighting the animal and methodological problems that arise from extrapolating indirect signs such as tracks or burrow movements as indicated by the displacement of strategically placed sticks positioned at the entrances of burrows (McIlroy, 1977). Traditional methods such as mark - recapture are difficult because of the size of the traps needed and the logistics of setting them (McIlroy, 1976), while novel methods such as hair snaring and identification of individuals using DNA technology can be expensive (Banks et al., 2003).

Since the European colonisation of Australia, riparian areas have been utilised for domestic cattle (Bos taurus) grazing, usually resulting in a decline in biodiversity (Jansen and Robertson, 2001; Robertson and Rowling, 2000). Cattle make disproportionate use of riparian areas relative to the uplands because riparian areas contain more palatable forage, are closer to water, and have favourable microclimatic conditions (Powell et al., 2000). In a study of cattle behaviour in British Columbia, riparian habitats were found to receive high levels of use during early morning foraging (Powell et al., 2000), while another (Smith et al., 1992) found that season may influence the amount of time cattle spend in the riparian zone, with greater use of riparian habitats in spring and summer. Little is known about cattle behaviour and habitat selection in temperate Australian ecosystems where riparian zones are usually accessible to cattle. In the United States, (Bryant, 1982) observed that when ambient temperature dropped and relative humidity increased, cattle moved out of riparian zones into the uplands. The effects of such meteorological variables as well as ecological variables on cattle behaviour in temperate Australian riparian systems have until now escaped attention. This is surprising, given that several studies have shown cattle trampling reduces leaf litter in riparian landscapes (Jansen and Robertson, 2001; Kramer et al., 2007), and damage to creek banks can be severe due to pressure by cattle.

Quantitative habitat modelling for cattle has relied largely on descriptions of the quality and patterns of forage use (Roath and Krueger, 1982). Gillen et al. (1985) used time - lapse Super $8 \mathrm{~mm}$ movie cameras to monitor cattle in riparian meadows, but analysis of the film was time consuming and the time of day of cattle activity could only be estimated by first counting all the frames in a day and calculating the mid point for that day (solar noon) (Gillen et al., 1985).

Camera - trapping has been successfully used throughout the world for studying a wide range of elusive animals when compared to more traditional methods (Bowkett et 
al., 2007; Carbone et al., 2001; O'Brien et al., 2003; Rios - Uzeda et al., 2007; Sanderson and Trolle, 2005) and has proven useful in providing detailed species inventories in parks and forests, where it has a high detection efficiency and has recorded species otherwise undetected (Giman et al., 2007; Yasuda, 2004). Camera trapping shows promise not only for providing an accurate measure of wombat abundance and habitat use, but also for providing a unique opportunity to simultaneously document the activity of domestic cattle in relation to the same set of ecological and meteorological variables.

In this study, camera - trap data was used to explore ecological and meteorological factors affecting habitat use by wombats and cattle in Eastern Riverine Forest landscapes (Keith, 2004) of southeastern New South Wales. Eastern Riverine Forests are extensive and important biological communities in south eastern Australia, although considerable clearing of these forests has occurred as a by-product of agricultural development of adjacent land (Keith, 2004).

\section{Materials and methods}

\section{Study area}

The study was conducted in Kangaroo Valley, New South Wales (34 $43^{\prime}$ 'S., $150^{\circ} 31^{\prime}$ 'E.) which was extensively cleared for dairy farming in the mid to late $1800 \mathrm{~s}$ (Griffith, 1986). Remnant ribbons of native Eastern Riverine Forest still occur (Keith, 2004) although now interspersed with invasive exotic plants. Deep alluvial soils occur on the floodplains and gleyed podzolic soils and soloths occur on the lower terraces and in depressions (Hazelton, 1992). The average annual rainfall measured at the Nowra weather station $24 \mathrm{~km}$ south of the study area is $1110 \mathrm{ml}$. The average maximum and minimum air temperatures are $25.8{ }^{\circ} \mathrm{C}$ and $16.3{ }^{\circ} \mathrm{C}$ in February and $15.8{ }^{\circ} \mathrm{C}$ and $6.2{ }^{\circ} \mathrm{C}$ in July (Bureau of Meteorology, 2006).

\section{Site selection}

Eight independent streambank study sites (each $100 \mathrm{~m}$ in length) were used for the study. Based on a survey of wombat burrows along riparian areas in Kangaroo Valley (Borchard et al., In Press) where mean burrow abundance was 5.4 per $100 \mathrm{~m}(\mathrm{n}=76$, s.d. 4.4), the eight sites were categorised as 'low' and 'high' wombat burrow abundance. Low abundance sites had $\leq 6$ burrows per $100 \mathrm{~m}$, while high abundance sites had $\geq 9$ burrows per $100 \mathrm{~m}$. Four sites had low levels of cattle trampling while the other four sites had high levels based on categories of cattle impact in riparian systems established in the above survey. The low cattle-impact sites (Category 1) were recognised as follows: impact restricted to tracks, tracks used only intermittently, soils generally undisturbed by hard hooves. The high cattle-impact sites (Category 4) were defined as follows: few vegetated areas undisturbed, tracks are heavily used, soils highly disturbed or compacted. Independently, the respective landholders provided information on the numbers of cattle that had access to each site over the last 15 years that corroborated these categories. Thus, sites categorised as low cattle-impact had $x$, $^{-}$ $=5.4$ (s.e. 12.6) cattle visits per day over 15 years, whereas the equivalent visitation rate in high cattle-impact sites was $x,^{-}=79.2$ (s.e. 12.6) cattle per day.

To ensure biological independence the distance between sites was at least $350-400$ $\mathrm{m}$. This distance was based on the maximum distance of $300 \mathrm{~m}$ travelled by radio 
collared wombats in a study undertaken in Kangaroo Valley by (Giles and Lonnon, 1999), and on a similar distance (estimated after linear conversion of average wombat home range areas) at Buccleuch State Forest, New South Wales (McIlroy, 1973). Standard agricultural fencing provided the boundaries for cattle.

\section{Camera trapping}

Two motion - sensing infrared - triggered Trapacameras (comprising Canon Sure Shot BF-10, $35 \mathrm{~mm}$ cameras) were used (Prof. Lineu Prestes, Cidade Universitaria Sao Paulo, Brazil). Prior to setting up in the field the sensitivity of the two cameras was calibrated by adjusting the mechanical potentiometers to ensure that daylight sensitivity and time delay between exposures was uniform between both cameras. Cameras were set to take pictures $24 \mathrm{~h}_{\text {day }}{ }^{-1}$ on 400 ASA colour print film, with a 90 second delay between exposures. The date and time of each exposure were shown on the photo print. Camera trap surveys were conducted between July 2006 and August 2007. Beginning at the first site, camera trap stations were located approximately $30 \mathrm{~m}$ and $70 \mathrm{~m}$ along a well worn track running parallel to stream flow along each $100 \mathrm{~m}$ streambank site over 7 days. On the afternoon of the $7^{\text {th }}$ day the cameras were collected and positioned in the same manner at the next site, then sequentially moved from site to site until all 8 sites were surveyed, before returning to the first site to repeat the procedure. In this manner, camera trapping was conducted at each site every 8 weeks. To reduce the possibility of running out of film before the end of the 7 day period, 36 exposure films were used exclusively and replaced regularly when approximately 20 photos had been taken. During the course of sampling no films were ever completely used within 7 days, thus ensuring an absolute measure of animal activity, and negating the need to calculate camera - trap rate (Bowkett et al., 2007). The positions selected along the site were random with respect to wombat and cattle use, but the specific camera location was selected so as to have an open field of view to maximize photographic capture rate. Therefore, based on the method used by (Bowkett et al., 2007) the adopted strategy was a compromise between completely random sampling and subjective selection of the mode of habitat use by wombats and cattle.

An intermission length of 60 minutes was used to reduce the number of consecutive photographs triggered by the same animal(s) within a short period of time. (Otani, 2002; Yasuda, 2004). All species recorded were identified after comparison with (Strahan, 1988) and (Simpson and Day, 1996). An advantage of camera trapping is that individual cattle may be distinguishable by patterns in coat colour as has been done with Tigers (Panthera tigris) in Indian forests (Karanth and Nichols, 1998). Wombats may also be distinguishable by wounds or scars, which are a common feature of wombats in high density populations in agricultural environments (Skerratt et al., 2004).

\section{Ecological variables}

Ecological variables were measured in January 2006 at each site containing a pair of camera traps. Variables were measured using a line transect method from the top of the stream bank to the water level, every $10 \mathrm{~m}$ along the $100 \mathrm{~m}$ stream bank site and at right angles to the stream flow. Starting from the top of the stream bank a $1 \mathrm{~m}^{2}$ quadrat was placed continuously along each metre of the transect and the following variables were measured within each quadrat then averaged across each site: percentage litter cover, average litter depth, number of cattle hoof prints. Upper and lower canopy cover was 
estimated at each quadrat position using the method described by (Walker and Hopkins, 1984).

\section{Meteorological variables}

Meteorological variables gained from the Australian Bureau of Meteorology, including rainfall, humidity and air temperature, were assigned to the time and date recorded of each animal photographed. Due to the high variability of rainfall traditionally recorded across Kangaroo Valley, rainfall records were collected from 1 of 3 recording stations no greater than 2 kilometres from any of the study sites, and then assigned to each photograph. Air temperature and humidity records (continuously upgraded every 30 minutes) at HMAS Albatross, Nowra (24 kilometers to the south of the study area) were also assigned to each photograph.

\section{Statistical analysis}

Descriptive statistics supported by single variable chi square tests of independence were computed to examine the distribution and characteristics of all variables. Logistic regression analyses were then used to examine the occurrence of cattle and wombats at each site in relation to the measured variables. Several variables were not included in the model because a regression analysis showed that there was little variation between the observed values and that they were found to consist of linear combinations of other variables (Table 1). A stepwise selection method was therefore used, in order to obtain a model that was comprised of all significant variables while remaining parsimonious.

The logistic regression model was fitted such that if the species was a wombat it was assigned a value of 1 whereas if it was a cow it was assigned a value of 0 . In order to determine which variables affected whether a cow or wombat was detected, a stepwise selection method was implemented. The critical value for entry and removal from the model was set at 0.05 . The interpretation was made with respect to log-odds as the logistic regression model uses a logit link to make the model linear (logit link $=\log$ (odds) $=\log (\mathrm{P} /(1-\mathrm{P})$ where $\mathrm{P}$ is the probability of detecting a wombat and $1-\mathrm{P}$ is the probability of observing a cow). In order to interpret the results in terms of the likelihood of detecting each species, there was a need to exponentiate the coefficient for each variable. The data analysis was performed using SAS (2003).

\section{Results}

The cameras detected 468 photographs of wombats and 106 of cattle. Wombats and cattle were more frequently detected in the summer and winter than in other seasons (Table 2). Smaller numbers of photographs were taken of another 11 species; these are not considered in the analyses presented below.

Wombats were detected most often on streambanks during time periods 1 and 2 while cattle were detected more during time periods 3 and 4 (Table 3). Among the different site classifications, cattle were detected more frequently in the low wombat and high cattle locations $(n=48)$ whereas wombats were detected more often at low wombat and low cattle sites $(n=155)$. This was followed closely by high wombat and low cattle $(\mathrm{n}=136)$ and high wombat and high cattle $(\mathrm{n}=110)$ locations (Table 3$)$. The number of species detections was dependent on site classification $(\mathrm{H} / \mathrm{H}, \mathrm{H} / \mathrm{L}, \mathrm{L} / \mathrm{H}, \mathrm{L} / \mathrm{L})$, 
season $(\mathrm{P}<0.0001)$, and time of day $(\mathrm{P}<0.0001)$ but the season and time of day interaction was not significant $(\mathrm{P}=0.1393)$.

Table 1. Ecological and meteorological variables recorded from eight riparian sites in Kangaroo Valley, NSW, and used to predict wombat and cattle abundance, prior to stepwise selection method

\begin{tabular}{l|c|c|c|c|c}
\hline Variable & DF & B & SE & Chi square & p \\
\hline Intercept & 1 & 18.0501 & 8.4382 & 4.5758 & 0.0324 \\
Time 1 (1900-0059 hrs) & 1 & -1.6366 & 0.2973 & 30.3104 & $<.0001$ \\
Time 2 (0100-0700 hrs) & 1 & -1.9427 & 0.3523 & 30.4083 & $<.0001$ \\
Time 3 (0701-1200 hrs) & 1 & 2.7518 & 0.4804 & 32.8138 & $<.0001$ \\
Humidity & 1 & -0.0448 & 0.0134 & 11.1468 & 0.0008 \\
Avg. lower canopy & 1 & -0.6607 & 0.5439 & 1.4754 & 0.2245 \\
Summer & 1 & 1.4398 & 0.5062 & 8.0908 & 0.0044
\end{tabular}

Variables below, made up of linear combinations of other variables not presented to regression

\begin{tabular}{|c|c|c|c|c|c|}
\hline \multicolumn{6}{|c|}{ models* } \\
\hline Rainfall & 1 & 0.0169 & 0.0145 & 1.3582 & 0.2439 \\
\hline Air temp & 1 & 0.019 & 0.064 & 0.0883 & 0.7664 \\
\hline Avg. upper canopy & 1 & 0.0443 & 2.3357 & 0.0004 & 0.9849 \\
\hline Litter cover & 1 & 2.5425 & 7.942 & 0.1025 & 0.7489 \\
\hline Litter depth & 1 & -58.873 & 208.6 & 0.0797 & 0.7778 \\
\hline Cattle hoof print & 1 & -0.0792 & 10.0826 & 0.0001 & 0.9937 \\
\hline Autumn & 1 & -0.7924 & 0.3841 & 4.2567 & 0.0391 \\
\hline Spring & 1 & 0.2132 & 0.3124 & 0.4655 & 0.495 \\
\hline
\end{tabular}

* The lower section of the table lists redundant variables which were largely made up of linear combinations of other variables and therefore were not presented to regression models. (The categorical variables Time 4 and the winter season were used as reference categories, and are not shown.)

Table 2. Total number of times all species were detected across all seasons at all sites with wombats and cattle shown in bold

\begin{tabular}{l|c|c|c|c|c}
\hline \multicolumn{1}{c|}{ Species } & $\begin{array}{c}\text { Total } \\
\text { detections }\end{array}$ & Spring & Summer & Autumn & Winter \\
\hline Cat (Felis catus) & 22 & 9 & 2 & 2 & 9 \\
Cattle (Bos taurus) & $\mathbf{1 0 6}$ & $\mathbf{1 6}$ & $\mathbf{3 7}$ & $\mathbf{2 1}$ & $\mathbf{3 2}$ \\
Deer (Cervus spp.) & 4 & 4 & 0 & 0 & 0 \\
Egret (Ardea ibis) & 5 & 0 & 5 & 0 & 0 \\
Fox (Vulpes vulpes) & 26 & 3 & 5 & 6 & 12 \\
Lyrebird (Menura & 12 & 1 & 0 & 2 & 9 \\
novaehollandiae) & 15 & 4 & 7 & 3 & 1 \\
Possum (Trichosurus & 6 & 0 & 2 & 3 & 1 \\
vulpecula) & 1 & 1 & 0 & 0 & 0 \\
Rabbit (Oryctolagus & 16 & 5 & 8 & 2 & 1 \\
cuniculus) & 2 & 0 & 2 & 0 & 0 \\
Rodent (Rattus spp.) & & & & & \\
Wallaby (Wallabia bicolor) & $\mathbf{4 6 8}$ & $\mathbf{9 6}$ & $\mathbf{1 1 1}$ & $\mathbf{5 9}$ & $\mathbf{2 0 2}$ \\
$\begin{array}{l}\text { Water Dragon (Physignathus } \\
\text { lesueurii) }\end{array}$ & 1 & 0 & 1 & 0 & 0 \\
$\begin{array}{l}\text { Wombat (Vombatus ursinus) } \\
\text { Wood Duck (Chenonetta }\end{array}$ & & & & & \\
jubata) & & & & & \\
\hline
\end{tabular}


Table 3. Number of times each species was detected at different times during the day as well as at each site classification

\begin{tabular}{|c|c|c|c|c|c|c|c|c|}
\hline Species & Time1 & Time2 & Time3 & Time4 & $\mathbf{H} / \mathbf{H}$ & $\mathbf{H} / \mathbf{L}$ & $\mathbf{L} / \mathbf{H}$ & $\mathbf{L} / \mathbf{L}$ \\
\hline Cat & 7 & 9 & 2 & 4 & 3 & 9 & 9 & 1 \\
\hline Cattle & 20 & 9 & 32 & 45 & 17 & 14 & 48 & 27 \\
\hline Deer & 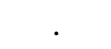 & 2 & 1 & 1 & . & . & & 4 \\
\hline Egret & & & & 5 & . & . & 5 & . \\
\hline Fox & 11 & 7 & 3 & 5 & 11 & 6 & 4 & 5 \\
\hline Lyrebird & & & 8 & 4 & 2 & . & . & 10 \\
\hline Possum & 8 & 7 & & & 2 & 8 & . & 5 \\
\hline Rabbit & 1 & 1 & 3 & 1 & 6 & . & . & . \\
\hline Rodent & 1 & & & & & & 1 & 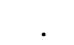 \\
\hline Wallaby & 4 & 9 & 1 & 2 & 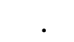 & 3 & . & 13 \\
\hline Water & . & . & 1 & 1 & 1 & . & 1 & $\cdot$ \\
\hline Dragon & & & & & & & & \\
\hline $\begin{array}{l}\text { Wombat } \\
\text { Wood Duck }\end{array}$ & 220 & 199 & $\begin{array}{l}8 \\
1\end{array}$ & 41 & 110 & $\begin{array}{c}136 \\
1\end{array}$ & 67 & 155 \\
\hline
\end{tabular}

Time $1=1900-0059$, Time $2=0100-0700$, Time $3=0701-1200$, Time $4=1201-1859$.

$\mathrm{H} / \mathrm{H}=$ High wombat/High cattle, $\mathrm{H} / \mathrm{L}=$ High wombat/Low cattle, $\mathrm{L} / \mathrm{H}=$ Low wombat/High cattle, $\mathrm{L} / \mathrm{L}=$ Low wombat/Low cattle.

The relationships between the use of streambanks by cattle and wombats and independent variables in riparian systems

The meteorological and ecological variables that had a significant effect on the detection of a wombat or a cow were time of day, humidity, lower storey canopy cover and season (specifically, summer) (Table 4).

\section{The effect of season on streambank use by wombats and cattle at all sites}

In the summer there was a significant difference $(\mathrm{P}=0.0001)$ for the detection of cattle (Table 4). The model predicts that the likelihood of detecting a cow during the summer compared to the winter increases by $\exp (1.290)=3.63$ times, after accounting for the other variables in the model. There was no difference in the likelihood of detecting a cow during the spring compared to detecting a cow during the winter. This suggests the likelihood of detecting a cow compared to a wombat increases during the summer months when compared to the winter months.

Table 4. Estimates for variables in the logistic regression model fitted to wombat and cattle data

\begin{tabular}{l|c|c|c|c|c}
\hline Variables & DF & B & SE & Chi Square & p \\
\hline Intercept & 1 & 3.06 & .80 & 14.62 & .0001 \\
Time 1 & 1 & -1.47 & .27 & 30.05 & $<.0001$ \\
Time 2 & 1 & -1.94 & .32 & 36.45 & $<.0001$ \\
Time 3 & 1 & 2.42 & .39 & 38.03 & $<.0001$ \\
Humidity & 1 & -.05 & .01 & 23.16 & $<.0001$ \\
Avg. Lower Canopy Cover & 1 & -.14 & .03 & 23.69 & $<.0001$ \\
Autumn & 1 & -.70 & .35 & 4.07 & .0435 \\
Spring & 1 & .29 & .27 & 1.14 & .2848 \\
Summer & 1 & 1.29 & .33 & 15.11 & .0001 \\
\hline
\end{tabular}




\section{The effect of time of day on streambank use by wombats and cattle at all sites}

There was a significant difference between time 1 and time $4(\mathrm{P}<0.0001)$ regarding the detection of a cow. The model predicts that the likelihood of detection a cow was $\exp (-1.469)=0.23$ times as likely during the late night hours as during the afternoon hours. This suggests that it would be less likely to detect a cow during the late night hours (time 1) than during the afternoon hours (time 4). For time 2 the same conclusions can be drawn from the above results. For time 3, there was a significant difference $(\mathrm{P}<$ 0.0001 ) between time 3 and time 4 regarding the detection of cows. The model predicts that likelihood of detecting a cow during time 3 compared to time 4 increases by exp $(2.421)=11.26$ times, after accounting for the other variables in the model. This suggests that the likelihood of detecting a cow compared to detecting a wombat increases during the mid-morning hours when compared to afternoon hours.

\section{The effect of lower canopy cover on streambank use by wombats and cattle at all sites}

The likelihood of detecting a cow compared to detecting a wombat was $\exp (-0.143)$ $=0.87$ times as likely when the average lower canopy increases by 1 unit, after controlling for the other variables in the model.

\section{The effect of humidity on streambank use by wombats and cattle at all sites}

The likelihood of detecting a cow compared to detecting a wombat was exp (-0.047) $=0.95$ times as likely when the humidity increases by 1 unit, after controlling for the other variables in the model. While the likelihood is almost the same, its significance can be attributed to the small standard error which was observed to be equal to .01 (Table 4). This indicates that there was a smaller amount of variability between the observed humidity values.

\section{Discussion}

\section{The use of streambanks by wombats and cattle}

\section{Seasonal activity}

The activity of wombats and cattle on streambanks was more pronounced in summer and winter, with activity for wombats being particularly marked in winter. This latter result may be attributed to the winter dormancy in adjacent paddocks of the common summer-growing pasture grass, kikuyu (Pennisetum clandestinum), and the consequent need, at that time for wombats to search more actively then for food in the riparian buffer. In the warmer months, wombats were readily observed foraging in adjacent agricultural pastures on kikuyu, and this species appears to comprise their main diet at this time. In the study area, winter pastures usually comprise ryegrasses (Lolium perenne, Lolium rigidum) which are palatable but apparently not preferred by wombats (Evans et al., 2006). In addition to these observations, female wombats are more likely to travel parallel to the remnant riparian vegetation, remaining particularly close to the remnant vegetation for protection when they have young (Skerratt et al., 2004). The frequent detection of cattle in summer follows trends highlighted in previous studies (Bryant, 1982; Powell et al., 2000; Smith et al., 1992), and suggests that cattle gain shelter from high temperatures, as well as access to forage and water, in riparian. The high activity of cattle in winter probably reflects the controlled grazing rotations used 
by farmers, and the exploratory responses of animals just moved to new pastures (Arnold and Dudzinski, 1978).

\section{Time of day}

Although generally nocturnal, in cool climates wombats can be active in the mornings, as late as $1000 \mathrm{~h}$ (Triggs, 1996). This study showed, however, that wombats were active mainly on streambanks between $1900 \mathrm{~h}$ and $0700 \mathrm{~h}$, which is consistent with studies of wombats in other landscapes (Buchan and Goldney, 1998; McIlroy, 1973; Taylor, 1993). Cattle were detected more frequently between $0701 \mathrm{~h}$ and $1859 \mathrm{~h}$, which probably reflect the tendency for cattle to forage by day and rest and night.

\section{The effect of site classification on the use of streambanks by wombats and cattle}

The use of streambanks by wombats was consistently high across all site classifications, with the exception of the Low Wombat - High Cattle classification, where activity levels were some fifty percent lower than the average for other sites. While wombats can visit one to four burrows within their home range each night and up to thirteen over several weeks (McIlroy, 1973), observations at the study sites over three years revealed that most streambank burrows were abandoned at some time. Burrow abandonment at the Low Wombat sites therefore may result in lower activity by wombats on those sections of the streambank. Interestingly the highest wombat activity was at the Low Wombat - Low Cattle classification. Preliminary evidence suggests that the ecology of wombats at high densities in agricultural land differs from that of wombats at lower densities predominately confined to forest (Skerratt et al., 2004). Greater burrow sharing by wombats and the close proximity of feeding areas affecting ranging behaviour (Skerratt et al., 2004) may have influenced this result.

\section{The relationship of streambank use by wombats and cattle with meteorological variables}

Humidity had little effect on wombat activity, but did affect cattle. (Roath and Krueger, 1982) reported humidity to be the second most important variable next to time after sunrise in predicting cattle activity, and found that humidity thresholds dictated the initiation of morning activities such as grazing and bedding. A similar pattern emerged in the present study in which streambank use by cattle increased in the mornings. While cameras were never placed in or near obvious bedding areas, multiple photographs were often taken of the same cow grazing. One would assume that a key physiological response to humidity would be via a humidity - temperature interaction, but in the present study temperature was not a significant factor accounting for streambank use by cattle. Most studies have focussed on the combined temperature/ humidity effect on cattle health. However, (Cook et al., 1998) found that, in elk, humidity is probably as important as temperature in causing heat stress. Notwithstanding other important factors affecting use of streambanks by cattle, such as shade and access to water (Powell et al., 2000), it is likely that cattle use streambanks for the microclimatic gradients in relative humidity that characterise riparian environments (Brosofske et al., 1997). 


\section{The effect of ecological variables on streambank use by wombats and cattle}

The most significant ecological variable influencing wombat and cattle activity was lower canopy density. Lower canopy density preference by wombats coincides with a preference for lower canopy density for wombat burrow sites (Borchard et al., In Press) and supports, generally, the preference for vegetative cover throughout the landscape by wombats (Catling et al., 1998; McIlroy, 1973). The results shown in Table 4 indicate that there was little variation in the utilisation by wombats of sites with differences in lower storey canopy density. Wombats typically use well-worn travel paths (Triggs 1996) and, due to their stature, are able to penetrate and establish tracks in dense scrub, establishing corridors through to managed agricultural land (Downes et al., 1997). Table 4, however, indicates that cattle are more likely to be discouraged by lower storey canopy cover. This could be due to several reasons. First, canopy cover reduces light falling on the ground of the stream bank, and this may in turn reduce the amount of palatable plant material that is available. Overgrazing, too, may result in the growth of unpalatable, perennial woody weeds (Hood and Naiman, 2000). The physical obstructions posed by slope (Reichman and Aitchison, 1981; Roath and Krueger, 1982; Taylor et al., 1972) and vegetation density may also reduce access for cattle.

\section{Camera trapping as a measure of streambank use by wombats and cattle}

Camera traps are being used widely and increasingly as a survey tool by conservation biologists and wildlife managers to investigate differences in abundance of target species between habitats and land-use types (Bowkett et al., 2007; Lizcano and Cavelier, 2000). This study is the first to use camera traps to model simultaneously the abundance and habitat use of a common native species and domestic cattle. It has demonstrated clear associations between detections by camera trapping and quantifiable habitat characteristics for wombats and cattle. This study also supports the findings of recent similar work on other animals where great potential has been shown with camera trapping for fine-scale habitat analysis (Bowkett et al., 2007; Di Bitetti et al., 2006). In comparison with other methods, camera traps have clear advantages for researchers including decreased time and costs associated with field work and better detection of nocturnal species, such as wombats (McIlroy, 1973). Assessing streambank use with camera trapping assumes that differences in 'trap' rate represent selection of surrounding habitat rather than unmeasured microhabitat features such as water sources (Bowkett et al., 2007). Potentially, animals may regularly visit unsuitable habitat to access important resources. In this study, cameras that were positioned on tracks at the sites with a denser lower storey cover could have resulted in a higher trap rate for those areas.

Acknowledgements. Thanks to Martin Barugel for assistance with the statistical analysis, and thanks to Dr Ian Wright, Dr Chris Dickman and Dr John McIlroy for reviewing early drafts. 


\section{REFERENCES}

[1] Arnold, G.W., Dudzinski, M.L. (1978): Ethology of free ranging domestic animals. Elsevier Scientific Publications, New York.

[2] Banks, S., Hoyle, S.D., Horsup, A., Sunnucks, P., Taylor, A.C. (2003): Demographic monitoring of an entire species (the northern hairy - nosed wombat, Lasiorhinus kreffti) by genetic analysis of non - invasively collected material. - Animal Conservation 6: 101107.

[3] Borchard, P., Collins, D. (2001): Environmental management of the Common Wombat Vombatus ursinus: a case study in the Shoalhaven Region, southeastern New South Wales, Australia. - International Journal of Ecology and Environmental Sciences 27: 185 $-190$.

[4] Borchard, P., Mc Ilroy, J.C., McArthur, C. (In Press): Links between riparian characteristics and the abundance of common wombat (Vombatus ursinus) burrows in an agricultural landscape - Wildlife Research.

[5] Bowkett, A.E., Rovero, F., Marshall, A.R. (2007): The use of camera - trap data to model habitat use by antelope species in the Udzungwa Mountain forests, Tanzania. - African Journal of Ecology 1-9.

[6] Brosofske, K.D., Chen, J., Naiman, R.J., Franklin, J.F. (1997): Harvesting effects on microclimatic gradients from small streams to uplands in Western Washington. Ecological Applications 7: 1188-1200.

[7] Bryant, L.D. (1982): Response of livestock to riparian zone exclusion. - Journal of Range Management 35: 780-785.

[8] Buchan, A., Goldney, D.C. (1998): The Common Wombat Vombatus ursinus in a fragmented landscape. - In: Wells, R.T. and Pridmore, P.A.(eds) Wombats, Surrey Beatty and Sons, Chipping Norton, Sydney.

[9] Carbone, C., Christie, S., Conforti, K., Coulson, T., Franklin, N., Ginsberg, J.R., Griffiths, M., Holden, J., Kawanishi, K., Kinnaird, M., Laidlaw, R., Lynam, A., Macdonald, D.W., Martyr, D., McDougal, C., Nath, L., O'Brien, T., Seidensticker, J., Smith, D.J.L., Sunquist, M., Tilson, R., Wan Shahruddin, W.N. (2001): The use of photographic rates to estimate densities of tigers and other cryptic mammals. - Animal Conservation 4: 75-79.

[10] Catling, P.C., Burt, R.J. (1995): Studies of the ground- dwelling mammals of Eucalypt forests in South-eastern New South Wales: the effect of habitat variables on distribution and abundance. - Wildlife Research 22: 271-288.

[11] Cook, J.G., Irwin, L.L., Bryant, L.D., Riggs, R.A., Thomas, J.W. (1998): Relations of forest cover and condition of elk: A test of the thermal cover hypothesis in summer and winter. - Wildlife Monographs 141: 1-61.

[12] Di Bitetti, M.S., Paviolo, A., De Angelo, C. (2006): Density, habitat use and activity patterns of ocelots (Lepardus pardalis) in the Atlantic Forest of Misiones, Argentina. Journal of Zoology 270: 153-163.

[13] Downes, S.J., Handasyde, K.A., Elgar, M.A. (1997): The use of corridors by mammals in fragmented Australian eucalypt forests. - Conservation Biology 11: 718-726.

[14] Evans, M.C., Macgregor, C., Jarman, P.J. (2006): Diet and feeding selectivity of common wombats. - Wildlife Research 33: 321-330.

[15] Giles, J.R., Lonnon, E.M. (1999): Status and management of the Common Wombat population in Kangaroo Valley, NSW: a report on streambank erosion and wombat population size in Kangaroo Valley. - The Zoological Parks Board of NSW Conservation Research Centre.

[16] Gillen, R.L., Krueger, W.C., Miller, R.F. (1985): Cattle use of riparian meadows in the Blue Mountains of Northeastern Oregon. - Journal of Range Management 38: 205-209. 
[17] Giman, B., Stuebing, R., Megum, N., Mcshea, W.J., Stewart, C.M. (2007): A camera trapping inventory for mammals in a mixed use planted forest in Sarawak. - The Raffles Bulletin of Zoology 55: 209-215.

[18] Griffith, J. (1986): A History of Kangaroo Valley. - Kangaroo Valley Historical Society.

[19] Hazelton, P.A. (1992): Soil Landscapes of the Kiama 1:100,000 Sheet. - Department of Conservation and Land Management (Incorporating the Soil Conservation Service of NSW). Sydney.

[20] Hood, W.G., Naiman, R.J. (2000): Vulnerability of riparian zones to invasion by exotic vascular plants. - Plant Ecology 148: 105-114.

[21] Jansen, A., Robertson, A.I. (2001): Relationships between livestock management and the ecological condition of riparian habitats along an Australian floodplain river. - Journal of Applied Ecology 38: 63-75.

[22] Karanth, K.U., Nichols, J.D. (1998): Estimation of Tiger densities in India using photographic captures and recaptures. - Ecology 79: 2852-2862.

[23] Keith, D.A. (2004): Ocean Shores to Desert Dunes: The Native Vegetation of New South Wales and the ACT. - Department of Environment and Conservation (NSW), Sydney.

[24] Kramer, A., Reich, P., Lake, P.S. (2007): Preliminary insights into the status of ground dwelling terrestrial arthropods at sites representing three riparian conditions. - Ecological Management and Restoration 8: 147-150.

[25] Lizcano, D.J., Cavelier, J. (2000): Daily and seasonal activity of the Mountain Tapir (Tapirus pinchaque) in the Central Andes of Colombia. - Journal of Zoology 252: 429435.

[26] Lunney, D., O'Connell, M. (1988): Habitat selection by the Swamp Wallaby, Wallabia bicolor, the Red-necked Wallaby, Macropus rufogriseus, and the Common Wombat, Vombatus ursinus, in logged, burnt forest near Bega, New South Wales. - Australian Wildlife Research 15: 695-706.

[27] Marks, C.A., Carolan, J., Leighty, R. (1989): The pest behaviour and management of the Common Wombat Vombatus ursinus in North Eastern Victoria. - Graduate School of Environmental Science, Monash University, Clayton, Victoria.

[28] McIlroy, J.C. (1973): Aspects of the ecology of the Common Wombat Vombatus ursinus (Shaw 1800). - Ph.D. Thesis, Australian National University, Canberra.

[29] McIlroy, J.C. (1976): Aspects of the ecology of the Common Wombat Vombatus ursinus I. Capture, handling, marking and radio-tracking techniques. - Australian Wildlife Research 3: 105-116.

[30] McIlroy, J.C. (1977): Aspects of the ecology of the Common Wombat Vombatus ursinus II. Methods for estimating population numbers. - Australian Wildlife Research 4: 223228.

[31] Murray, D.W. (2001): Predicting the distribution and abundance of the Common Wombat (Vombatus ursinus Shaw 1800) using case based reasoning (CBR) analysis of environmental factors. - Ph.D. Thesis, University of New England, Armidale.

[32] O'Brien, T.G., Kinnaird, M.F., Wibisono, H.T. (2003): Crouching tigers, hidden prey: Sumatran tiger and prey populations in a tropical forest landscape. - Animal Conservation 6: 131-139.

[33] Otani, T. (2002): Seed dispersal by Japanese Marten Martes melampus in the subalpine

[34] shrubland of northern Japan. - Ecological Research 17: 29-38.

[35] Powell, G.W., Cameron, K.J., Newman, R.F. (2000): Analysis of livestock use of riparian areas: literature review and research needs assessment for British Columbia. - Victoria, B.C. Working paper. 52/2000.

[36] Reichman, O.J., Aitchison, S. (1981): Mammal trails on mountain slopes: Optimal paths in relation to slope angle and body weight. - The American Naturalist 117: 416-420.

[37] Reichman, O.J., Seabloom, E.W. (2002): The role of pocket gophers as subterranean ecosystem engineers. - Trends in Ecology and Evolution 17: 44-49. 
[38] Rios-Uzeda, B., Gomez, H., Wallace, R.B. (2007): A preliminary density estimate for Andean bear using camera - trapping methods. - Ursus 18: 124-128.

[39] Roath, L.R., Krueger, W.C. (1982): Cattle grazing and behaviour on a forested range. Journal of Range Management 35: 332-339.

[40] Robertson, A.I., Rowling, R.W. (2000): Effects of livestock on riparian zone vegetation in an Australian dryland river. - Regulated Rivers: Research and Management 16: 527541.

[41] Roger, E., Laffran, S.W., Ramp, D. (2007): Habitat selection by the common wombat (Vombatus ursinus) in disturbed environments: Implications for the conservation of a 'common species'. - Biological Conservation 137: 437-449.

[42] Sanderson, J.G., Trolle, M. (2005): Monitoring elusive animals. - American Scientist 93:148-155.

[43] SAS. (2003): SAS/STATS user's guide. - SAS Institute Incorporated, Cary, NC.

[44] Simpson, K., Day, N. (1996): Field guide to the birds of Australia. - Viking, Melbourne.

[45] Skerratt, L.F., Skerratt, J.H.L., Banks, S., Martin, R., Handasyde, K. (2004): Aspects of the ecology of common wombats (Vombatus ursinus) at high density on pastoral land in Victoria. - Australian Journal of Zoology 52: 303-330.

[46] Smith, M.A., Rodgers, J.D., Dodd, J.L., Skinner, Q.D. (1992): Habitat selection by cattle along an ephemeral channel. - Journal of Range Management 45: 385-390.

[47] Strahan, R. (1988): The complete book of Australian mammals. - Angus and Robertson, Sydney.

[48] Taylor, C.R., Caldwell, S.I., Rowntree, V.J. (1972): Running up and downhills: Some consequences of size. - Science 178: 1096-1097.

[49] Taylor, R.J. (1993): Observations on the behaviour and ecology of the common wombat Vombatus ursinus in Northeast Tasmania. - Australian Mammalogy 16: 1-7.

[50] Triggs, B. (1996): The Wombat: Common Wombats in Australia. - University of New South Wales Press Ltd., Sydney.

[51] Walker, J., Hopkins, M.S. (1984): Vegetation. - In: Australian soil and land survey field handbook. Inkata Press, Sydney.

[52] Yasuda, M. (2004): Monitoring diversity and abundance of mammals with camera traps: a case study on Mount Tsukuba, central Japan. - Mammal Study 29: 37-46. 